\title{
S-haplotypes and Genetic Diversity in 'Danji' Radish (Raphanus sativus L. var. hortensis)
}

\author{
Yulkyun Ahn ${ }^{1}$, Hyukjun Kim², Dongyeop Han², and Younghoon Park ${ }^{2,3 *}$ \\ ${ }^{1}$ Vegetable Research Division, National Institute of Horticultural \& Herbal Science, Suwon 440-706, Korea \\ ${ }^{2}$ Department of Horticultural Bioscience, Pusan National University, Miryang 627-706, Korea \\ ${ }^{3}$ Life and Industry Convergence Research Institute, Pusan National University, Miryang 627-706, Korea
}

\begin{abstract}
The distribution of S-haplotypes and genetic relationships were evaluated for 47 accessions of 'Danji' radish (Raphanus sativus L. var. hortensis Baker f. gigantissimus Makino) originating from Jeju Island in South Korea. A total of 22 S-haplotype-specific SCAR markers for the S locus glycoprotein (SLG) and S receptor kinase (SRK) loci were tested, and six primer sets amplified locus-specific PCR fragments from at least one 'Danji' radish accession. S5 and S21 alleles atthe SLG locus were the most frequently distributed, and detected from $87.5 \%$ and $64.6 \%$ of the accessions, respectively. The frequency of the class-II haplotype at the SLG locus was 75\%, more frequent than the class-I haplotype. The S23 allele at the SRK locus was detected from 7 accessions. Grouping of the accessions based on S-allele composition revealed three major groups, while 8 accessions showed a unique allelic composition. The genetic diversity of 47 'Danji' radishes and 1 'Gwandong' radish were also evaluated with 38 RAPD primers. A total of 312 bands were scored, and showed that 138 bands (44.2\%) were monomorphic among the accessions, whereas 174 (55.8\%) bands were polymorphic. Polymorphism rates ranged from 0.2 to 1.0, indicating significant variations in detecting polymorphism across RAPD primers. The genetic similarity coefficients among all pairs of the 48accessions varied from 0.62 to 0.93 , and $42 \%$ of the comparisons exhibited values higher than 0.85 . All the cultivars could be distinguished based on the DNA fingerprints revealed by RAPD. The comparisons between the dendrograms based on S-haplotypes and RAPDs indicate an unrelated and sporadic distribution for several accessions; however, there was a tendency for accessions with the same S-allelic composition to group into the same cluster.
\end{abstract}

Additional key words: Brassicaceae, Cruciferous vegetables, DNA marker, self-incompatibility, S-locus

\section{Introduction}

'Danji' radish (Raphanus sativus L. var. hortensis Baker f. gigantissimus Makino, $2 \mathrm{n}=2 \mathrm{x}=18$ ) is an annual plant in the Brassicaceae family, and is native to Jeju Island in Korea. 'Danji' radish had been used as vegetable before $F_{1}$ radish varieties became commercialized, but it is no longer cultivated on a large scale by farmers. This plant, however, shows several advantageous characteristics. The original form of 'Danji' radish had unique root characters, such as a round shape and big size (as much as 10-15 $\mathrm{kg}$ ), and was crispy enough to use in Kimchi. Different from $F_{1}$ radish cultivars, it is extremely late flowering, with a strong vigor and a thick, dark green mesophyll. 'Danji' radish cultivars have been maintained by home seed production by farmers. However, the present 'Danji' radish lost its own characteristics by pollination with the other pollens of $F_{1}$ varieties. Thus, restoring the original character of 'Danji' radish has required breeding for the development of commercially useful varieties.

Like other species of Cruciferous vegetables (e.g. cabbage, broccoli, turnip), the 'Danji' radish is a cross-pollinating crop. The prevention of self-fertilization and promotion of outcrossing are mainly controlled by a genetic mechanism called self-incompatibility (SI) (Bateman, 1955). SI acts by inhibiting the germination of pollen on stigma, or by inhibiting the elongation of the pollen tube in the styles based on protein-protein interactions (Nasrallah et al., 1970).

\footnotetext{
*Comesponding author: ypark@pusan.ac.kr

※ Received 19 August 2013; Revised 15 October 2013; Accepted 19 November 2013. This work was supported by Pusan National University Research Grant, 2013.

(C) 2014 Korean Society for Horticultural Science
} 
This mechanism is controlled by multiple interactions between many different alleles at a single locus (the $\mathrm{S}$ locus) (Nasrallah et al., 1991).

In breeding, SI is widely used for the production of $\mathrm{F}_{1}$ hybrids. The genetic mechanism of SI has been studied in several rapeseed cultivars. SI is controlled sporophytically by a single multi-allelic locus (the $\mathrm{S}$ locus). The S-locus consists of two linked genes expressed in the pistiland anther, the S locus glycoprotein (SLG) gene and the S receptor kinase (SRK), that are female determinants expressed in stigma papillae (Nasrallah et al., 1985; Rundle et al., 1993). The S locus cysteine-rich (SCR) gene andS locus protein 11 (SP11) are male determinants expressed in the anthers (Kakayama et al., 2001; Watanabe et al., 2000). In a SI reaction, the $S$ domain of the membrane-associated SRK forms a complex with the pollen-born SCR/SP11 protein. Formation of this complex leads to activation of the kinase domain of SRK, inducing a signal transduction cascade involving phosphorylation events, that finally lead to rejection of the pollen and preventing fertilization. Based on sequence polymorphisms, SLG alleles are divided into two classes (Nasrallah et al., 1991). The class-I haplotypes are dominant and have strong self-incompatibility, whereas the class-II haplotypes are considered recessive and display a weak self-incompatible phenotypic effect (Nasrallah and Nasrallah, 1993). However, when a female determinant interacts with a male determinant of a different haplotype, no SI is created.

For the identification and classification of $\mathrm{S}$ haplotypes, the PCR-RFLP method was developed (based on DNA sequence variation in the SLG and SKR gene) and successfully used in Brassica and Raphanus (Lim et al., 2002). Later, these S-allele-specific PCR-RFLPs were converted to Sequence characterized amplified region (SCAR) markers that provide easier assessment of various haplotypes of the SLG and SKR genes. Random amplified polymorphic DNAs (RAPDs) can be extremely useful for marker-assisted selection (MAS) of important traits and DNA fingerprinting for genetic diversity assessment. DNA fingerprinting has been widely used to group germplasm with similar genetic constitution and identify parental combinations that could potentially create maximal genotypic variability in their progenies to achieve advances in selection. Genotypic differences can also be used for cultivar identification, germplasm management, and protection of the plant breeder's intellectual property rights (Lombard et al., 2000).

Despite its potential for revealing new sources of radish cultivar and breeding needs, no study has reported the identification and allele frequency of S-haplotypes in the 'Danji' radish population of Jeju Island. In the present study, we identify S-haplotypes of 'Danji' radish conserved on Jeju Island through germplasm collection and characterize its genetic diversity by using S-allele specific SCAR and RAPD markers.

\section{Materials and Methods}

\section{Plant Materials}

Plant materials include 47 accessions of 'Danji' radish collected on Jeju Island (and used as breeding materials) and one commercial radish cultivar, 'Gwandong' (Fig. 1).

\section{Genomic DNA Isolation}

Leaf tissue was ground in a $1.5 \mathrm{~mL}$ micro-centrifuge tube using steel beads and $600 \mu \mathrm{L}$ of DNA extraction buffer with a Tissue Lyser (QIAGEN, Venlo, Netherlands). The tube was incubated at $65^{\circ} \mathrm{C}$ for approximately $45 \mathrm{~min}$, $200 \mu \mathrm{L}$ of $7.5 \mathrm{M}$ ammonium acetate added, and then the tube was placed on ice for 15-20 min. The lysate was centrifuged at $14,240 \times \mathrm{g}$ for $10 \mathrm{~min}$, and the supernatant transferred to a new $1.5 \mathrm{~mL}$ tube containing $5 \mu \mathrm{L}$ of glycogen solution $\left(5 \mathrm{mg} \cdot \mathrm{mL}^{-1}\right)$ and $600 \mu \mathrm{L}$ of isopropanol. After centrifugation at $14,240 \times g$ for $10 \mathrm{~min}$, the liquid was carefully decanted, and the DNA pellet washed with $300 \mu \mathrm{L}$ of $70 \%$ ethanol. The washed pellet was dried and resuspended in $200 \mu \mathrm{L}$ of $0.1 \mathrm{M}$ Tris. DNA quality and concentration were evaluated with a Nanodrop 1000 Spectrophotometer (Thermo Scientific, Pittsburgh, PA, U.S.A.).

\section{S-haplotype Identification}

For the identification of S-haplotypes, PCR primer sequence information was obtained from the National Center for

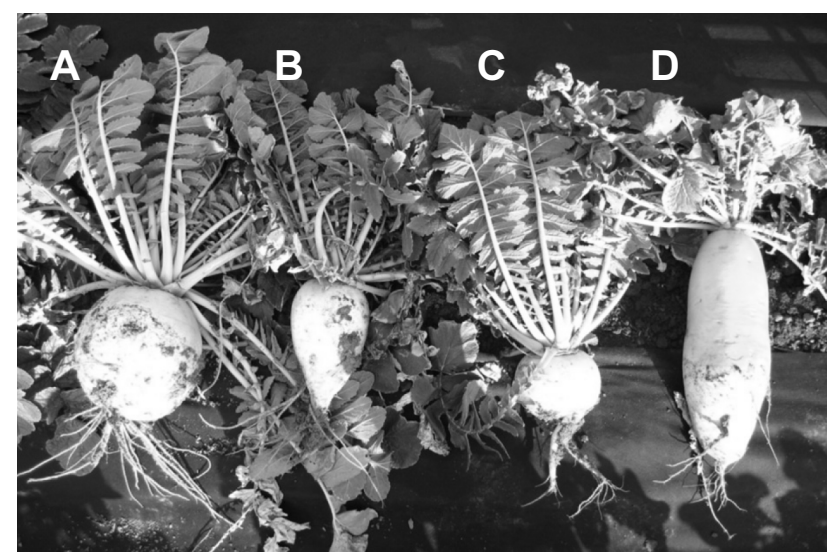

Fig. 1. Phenotypes of different accessions of the 'Danji' radish (A, B, and C; Raphanus sativus L. var. hortensis) and 'Gwandong' radish radish (D; Raphanus sativus L. var. sativus). 
Biotechnology Information (NCBI) database and primers synthesized by Bioneer Inc. (Daejeon, Korea). PCR was performed to amplify $\mathrm{S}$ allele-specific genes with the following cycling profile: 1 cycle of $15 \mathrm{~min}$ at $95^{\circ} \mathrm{C}$ for preheating, 35 cycles of $20 \mathrm{~s}$ at $95^{\circ} \mathrm{C}$ for denaturation, $40 \mathrm{~s}$ at an appropriate temperature for each primer (Table 1) for annealing, $1 \mathrm{~min}$ at $72^{\circ} \mathrm{C}$ for extension, and 1 cycle of $5 \mathrm{~min}$ at $72^{\circ} \mathrm{C}$ for an final extension step. PCR products were separated on a $1.5 \%$ agarose gel containing TBE at $120 \mathrm{~V}$ for $2 \mathrm{~h}$, and visualized under UV light after staining with ethidium bromide.

For DNA fingerprinting of 'Danji' radish cultivars, 40 10-mer RAPD primers were randomly chosen and tested for RAPD. PCR amplification for RAPD evaluation was performed in a total volume of $20 \mu \mathrm{L}$ containing $40 \mathrm{ng}$ of genomic DNA, each 10-mer primer at $1.25 \mu \mathrm{M}, 2.5 \mathrm{mM}$ $\mathrm{MgCl}_{2}$, 1X PCR buffer, $0.2 \mathrm{mM}$ dNTPs, and $1 \mathrm{U}$ of Taq polymerase (Solgent, Daejeon, Korea) with the following cycling profile: 1 cycle of $5 \mathrm{~min}$ at $95^{\circ} \mathrm{C}, 35$ cycles of 30 $\mathrm{s}$ at $95^{\circ} \mathrm{C}, 30 \mathrm{~s}$ at $40^{\circ} \mathrm{C}$, and $2 \mathrm{~min}$ at $72^{\circ} \mathrm{C}$, and 1 cycle of $3 \mathrm{~min}$ at $72^{\circ} \mathrm{C}$ for an extension step. PCR products were separated on a $1.0 \%$ agarose gel containing TBE at 80 $\mathrm{V}$ for $1 \mathrm{~h}$., and visualized under UV light after staining with ethidium bromide.

\section{Assessment of Genetic Diversity}

The polymorphic and monomorphic fragments were counted across all 48 accessions for each SCAR and RAPD primer. Only clearly readable bands with strong intensity were manually scored and included in the binary data matrix (i.e., 1 denoted a band was present, 0 denoted absence). All subsequent data analysis was performed using NTSYS-pc version $2.02 \mathrm{k}$. Pair-wise genetic similarity coefficients among the cultivars were calculated based on Nei-Li (Nei and

Table 1. List of primers used for PCR amplification of S-haplotypes from the S locus glycoprotein (SLG) and S receptor kinase (SRK) genes.

\begin{tabular}{|c|c|c|c|c|c|}
\hline \multirow{2}{*}{$\begin{array}{l}\text { Gene-S } \\
\text { haplotype }\end{array}$} & \multirow{2}{*}{ Primer } & \multicolumn{2}{|c|}{ Primer sequence (5'-3') } & \multirow{2}{*}{$\begin{array}{l}\text { Product } \\
\text { size }\end{array}$} & \multirow{2}{*}{$\begin{array}{c}\text { NCBI } \\
\text { Accession } \\
\text { number }\end{array}$} \\
\hline & & Forward & Reverse & & \\
\hline SLG-S1 & Slg01 & AGATCTCCGGTGGGTGGCAGAG & ССАСTTTTCCATATTCCTGGGATCG & 622 & AY052572.1 \\
\hline SLG-S2 & Slg02 & CGGCTTCTTCAGAACCAATTCCCGT & TCGCACTGTGAGTCCAATGG & 723 & AY052573.1 \\
\hline SLG-S4 & $\operatorname{Slg} 04$ & TACAGACAACGGAGAGGAGA & AACTGAAGCCATCCCGGTGA & 132 & AY052577.1 \\
\hline SLG-S5 & Slg05 & GGCAACAATCTTGTCTTGCTAGGT & ACGCGAAAATCCCGGTTGAGG & 289 & AY052578.1 \\
\hline SLG-S6 & Slg06 & CTGTTTCGTTCAGCCTTTTCG & ACATAGGTTCGCTCGGACAC & 179 & AY052574.1 \\
\hline SLG-S10 & $\operatorname{Slg} 10$ & CCTACGACAATTCTTACACCTGC & TGCATAGCCCACCGCTCTTC & 997 & AY052576.1 \\
\hline SLG-S11 & $\operatorname{Slg} 11$ & TGTCCTCCAAGGTCATTCCA & GACCAGAACACGTTCCACACCA & 558 & AY527399.1 \\
\hline SLG-S12 & $\operatorname{Slg} 12$ & TCTTGTCCTCCTTGGCCACT & CATGGACCGCTCCGATGCTC & 360 & AY527400.1 \\
\hline SLG-S21 & $\operatorname{Slg} 21$ & GGCAACAATCTTGTCCTGATTG & AACACGTTGATTCAAAAACTGATTTA & 350 & AY529650.1 \\
\hline SLG-S26 & $\operatorname{Slg} 26$ & ATTCGAAGGGGGTTGCCAGA & ACTCGATTCCGTTCCACGGTC & 82 & AY529652.1 \\
\hline SLG-S27 & Slg27 & TCTTGATTCTACATCGCCCTG & TTGATGTCGGGGTCGTCCATC & 807 & AY527402.1 \\
\hline SRK-S7 & Srk07 & TCTTGCAGAGAACAGACCAACCA & CCTGGCCATTTAGGCTGAGGA & 87 & AY052582.1 \\
\hline SRK-S8 & Srk08 & CACAATGAACGTGGTTGGAAC & CAGGATTGATCGTCGTCACACTGTC & 620 & AY052583.1 \\
\hline SRK-S9 & Srk09 & TCTTTGGAAGGGACACGAGT & TTTTTGCGAGGCGGTAAACT & 607 & AY052584.1 \\
\hline SRK-S15 & Srk15 & CTTTGAATAGCTCGAAGGTCTATAGA & CCAAACCACAGACGACATTG & 837 & AY534534.1 \\
\hline SRK-S16 & Srk16 & GCATTGACCCAGATGAGAAGATTC & GTTCCGATCGGAGTATCTGTGC & 395 & AY534535.1 \\
\hline SRK-S18 & Srk18 & CGCAATGAATGGATCTTCTCCGA & AGGATTCATCGCATCCAACTGCCT & 506 & AY534536.1 \\
\hline SRK-S20 & Srk20 & CTCGAGTAGGCAATCCAACG & GGTGTACTCGTTCATCGTCCAGGA & 51 & AY534537.1 \\
\hline SRK-S22 & Srk22 & GGCTGTGATTGATTCGTAGGAGA & CGAGAATACCCCATCCAGTGC & 383 & AY534538.1 \\
\hline SRK-S23 & Srk23 & CTTGGTTGTTGTATTGAGGCAGATG & CTCCTACAAATTGATCACAGCCAGA & 172 & AY534539.1 \\
\hline SRK-S30 & Srk30 & TGTAGGTAAAACCCGAAGGTC & CTTCCGATGCAACAACCTGG & 834 & AY534542.1 \\
\hline SRK-S31 & Srk31 & GAGGATTCAACAACTTGGACAACG & TCCAGTTAACCCATGCCTGT & 162 & AY534543.1 \\
\hline
\end{tabular}


Li 1979) and the Nei-Li similarity coefficient was calculated as $2 a /(n-d)$, where $a$ is the number of loci for which the bands is present, $d$ is the number of loci for which the band is absent, and $\mathrm{n}$ is the total number of loci. Dendrograms were constructed using the unweighted pair-group method with arithmetic averaging (UPGMA) clustering analysis of the genetic similarity coefficient matrices.

\section{Results and Discussion}

\section{S-allele Distribution of 'Danji' Radish}

The S-allele classification and distribution of 'Danji' radish accessions originating from Jeju Island were investigated with SCAR markers (Table 2 and Fig. 2). Among 22 Shaplotype-specific SCARs, only six primer sets amplified locus-specific PCR fragments from at least one accession. These primer sets were specific to S1, S2, S5, S10, and S21 haplotypes for the SLG locus and S23 for the SRK locus. All other primer sets failed PCR amplification, possibly due to nucleotide sequence variation in primer binding sites or the lack of any corresponding $\mathrm{S}$ allele in the genome.

For the SLG locus, the frequency of the class-II haplotype was $72 \%$, higher than the frequency of class-I. S5 and S21 were the most frequently distributed S-haplotypes and detected from $87.5 \%$ and $64.6 \%$ of the accessions investigated, respectively. Accessions containing both of these alleles accounted for $64.5 \%$. S23 for SRK was detected from only seven cultivars and all cultivars also contained SLG alleles.

Grouping of the accessions based on the S-allele composition revealed three major groups (Group A-1, A-2, and
A-3) consisting of 29 (Group A-1), 13 (Group A-2), and 6 (Group A-3) cultivars. Eight cultivars showed unique allelic compositions and could be distinguished from other cultivars.

Lim et al. (2006) reported the classification of S-haplotypes in commercial $F_{1}$ hybrid radish cultivars. Among 44 cultivars, almost half of the S-haplotypes in $\mathrm{F}_{1}$ hybrids contain the class-II haplotype. A high frequency of class-II haplotypes was also detected in 'Danji' radishes, indicating a close genetic relationship between these two species. It also indicates gene introduction by natural cross-pollination with radish $\mathrm{F}_{1}$ cultivars in which the class-II haplotypes of inbreds were frequently used as the parents of $F_{1}$ hybrid cultivars.

Although conventional test crosses need to be performed for the determination of $\mathrm{S}$ haplotypes in 'Danji' radishes, the results of this study can be useful for predicting the possibility of self-incompatibility and determining proper cross combinations for improving genetic diversity.

\section{Genetic Diversity by RAPD}

The genetic diversity of 47 'Danji 'radishes and 1 'Gwandong' radish were evaluated by using 38 RAPD primers (Table 3 and Fig. 2). Forty-eight accessions were genotyped with 38 randomly chosen RAPD primers. A total of 312 bands were scored, with 138 bands (44.2\%) monomorphic among the 60 cultivars, whereas 174 (55.8\%) polymorphic bands were identified. For each primer, an average of 8.2 bands was scored and an average of 45.7 polymorphic bands was detected. Polymorphism rates ranged from 0.2 to 1.0, indicating significant variations in detecting polymorphisms across the RAPD primers (Table 3).

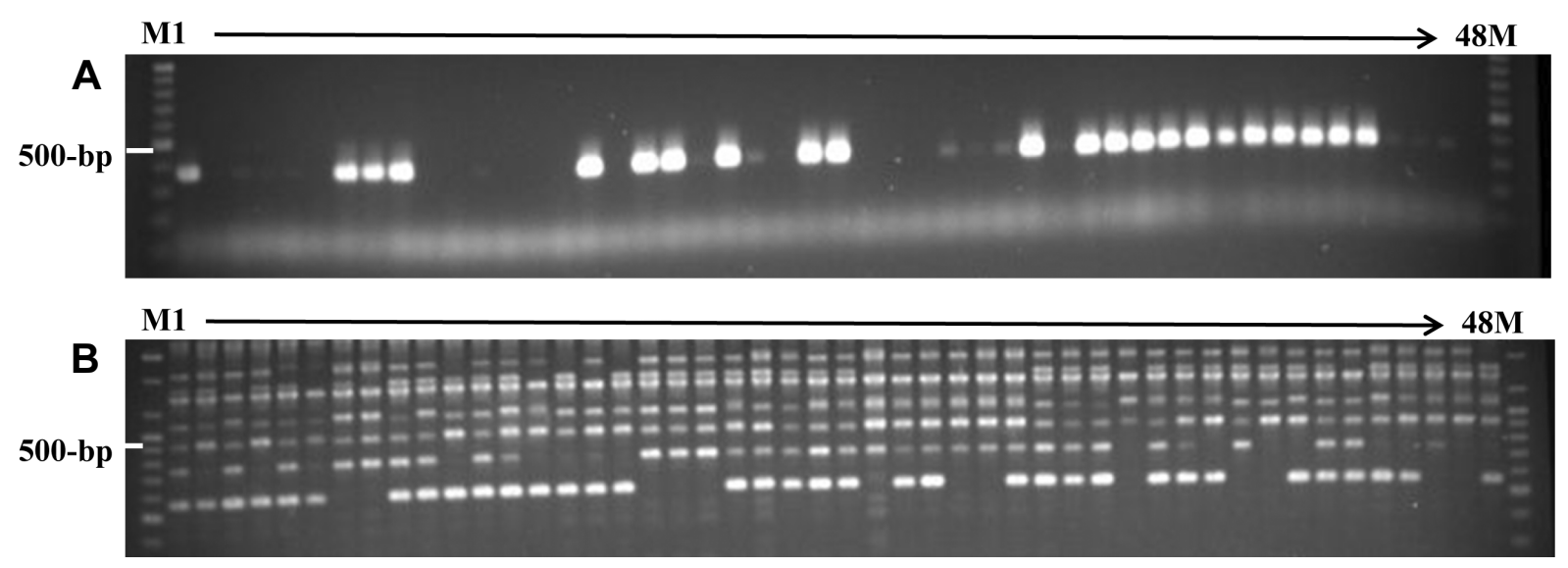

Fig. 2. Image of an agarose gel showing aS-haplotype specific marker and RAPDs. A, S-haplotype specific PCR bands amplified by the primer pair Slg21; B, RAPD bands amplified by the primer A01. M, 100-bp size marker; lane 1 to 48, DNA samples from Entry No. 1 to 48 (Table 2). 
Table 2. S-haplotype distribution from germplasm accessions of the 'Danji' radish (asseccion 1-47; Raphanus sativus L. var. hortensis) and 'Gwandong' radish (Raphanus sativus L. var. sativus).

\begin{tabular}{|c|c|c|c|c|c|c|c|}
\hline \multirow{2}{*}{$\begin{array}{l}\text { Entry } \\
\text { No. }\end{array}$} & \multirow{2}{*}{ Accession } & \multicolumn{6}{|c|}{ S haplotype specific primer (S haplotype $)^{z}$} \\
\hline & & Slg01 (S1) & Slg02 (S2) & Slg10 (S10) & Slg05 (S5) & Slg21 (S21) & Srk23 (S23) \\
\hline 1 & 3 & & & & $\mathbf{P}$ & $\mathbf{P}$ & \\
\hline 2 & 4 & & & & $\mathbf{P}$ & & \\
\hline 3 & 5 & & $\mathbf{P}$ & $\mathbf{P}$ & $\mathrm{P}$ & $\mathrm{P}$ & \\
\hline 4 & 6 & & & & $\mathrm{P}$ & $\mathrm{P}$ & \\
\hline 5 & 7 & & $\mathbf{P}$ & & $\mathrm{P}$ & $\mathrm{P}$ & \\
\hline 6 & 8 & & $\mathbf{P}$ & & & & \\
\hline 7 & 9 & & & & $\mathbf{P}$ & $\mathbf{P}$ & \\
\hline 8 & 10 & & $\mathrm{P}$ & & $\mathbf{P}$ & $\mathbf{P}$ & \\
\hline 9 & 11 & & $\mathrm{P}$ & $\mathbf{P}$ & $\mathbf{P}$ & $\mathbf{P}$ & \\
\hline 10 & 12 & & & $\mathbf{P}$ & & & \\
\hline 11 & 13 & & $\mathbf{P}$ & & $\mathrm{P}$ & & \\
\hline 12 & 14 & & $\mathbf{P}$ & & $\mathrm{P}$ & $\mathrm{P}$ & \\
\hline 13 & 15 & & $\mathbf{P}$ & $\mathbf{P}$ & $\mathrm{P}$ & & \\
\hline 14 & 16 & & & $\mathbf{P}$ & $\mathrm{P}$ & & \\
\hline 15 & 17 & & $\mathbf{P}$ & & $\mathrm{P}$ & & \\
\hline 16 & 18 & & & & $\mathbf{P}$ & $\mathbf{P}$ & \\
\hline 17 & 19 & & $\mathbf{P}$ & & $\mathrm{P}$ & & \\
\hline 18 & 20 & & & & $\mathbf{P}$ & $\mathbf{P}$ & \\
\hline 19 & 21 & & & & $\mathbf{P}$ & $\mathbf{P}$ & \\
\hline 20 & 22 & & & & $\mathrm{P}$ & & \\
\hline 21 & 23 & & & & $\mathbf{P}$ & $\mathbf{P}$ & \\
\hline 22 & 24 & $\mathbf{P}$ & & & $P$ & $\mathrm{P}$ & $\mathbf{P}$ \\
\hline 23 & 25 & $\mathbf{P}$ & & & & & $\mathbf{P}$ \\
\hline 24 & 26 & & & & $\mathbf{P}$ & $\mathbf{P}$ & \\
\hline 25 & 27 & & & & $\mathbf{P}$ & $\mathbf{P}$ & \\
\hline 26 & 28 & & $\mathbf{P}$ & & $\mathrm{P}$ & & \\
\hline 27 & 29 & & $\mathbf{P}$ & & $\mathrm{P}$ & & \\
\hline 28 & 30 & & $\mathbf{P}$ & & $\mathrm{P}$ & & \\
\hline 29 & 31 & & $\mathbf{P}$ & & $\mathrm{P}$ & & \\
\hline 30 & 32 & & $\mathbf{P}$ & & $\mathrm{P}$ & & \\
\hline 31 & 33 & & $\mathbf{P}$ & & $\mathrm{P}$ & & \\
\hline 32 & 34 & & & & $\mathbf{P}$ & $\mathbf{P}$ & \\
\hline 33 & 35 & & & & $\mathrm{P}$ & $\mathrm{P}$ & \\
\hline 34 & 36 & & $\mathbf{P}$ & & $\mathbf{P}$ & $\mathbf{P}$ & \\
\hline 35 & 37 & & & & $\mathbf{P}$ & $\mathbf{P}$ & \\
\hline 36 & 38 & & & & $\mathbf{P}$ & $\mathbf{P}$ & \\
\hline 37 & 39 & & & & $\mathbf{P}$ & $\mathbf{P}$ & \\
\hline 38 & 40 & & & & $\mathbf{P}$ & $\mathbf{P}$ & \\
\hline 39 & 41 & $\mathbf{P}$ & & & $\mathbf{P}$ & $\mathbf{P}$ & $\mathbf{P}$ \\
\hline 40 & 42 & $\mathbf{P}$ & & & $\mathbf{P}$ & $\mathbf{P}$ & $\mathbf{P}$ \\
\hline 41 & 43 & $\mathbf{P}$ & & & $\mathbf{P}$ & $\mathbf{P}$ & $\mathbf{P}$ \\
\hline 42 & 44 & & & & $\mathbf{P}$ & $\mathbf{P}$ & \\
\hline 43 & 45 & & & & $\mathbf{P}$ & $\mathbf{P}$ & \\
\hline 44 & 46 & $\mathbf{P}$ & & & $\mathbf{P}$ & $\mathbf{P}$ & $\mathbf{P}$ \\
\hline 45 & 47 & & & & $\mathbf{P}$ & $\mathrm{P}$ & \\
\hline 46 & 48 & & $\mathbf{P}$ & & & $\mathrm{P}$ & \\
\hline 47 & 50 & & & $\mathrm{P}$ & & $\mathrm{P}$ & \\
\hline 48 & Gwandong & $\mathbf{P}$ & & $\mathrm{P}$ & & & $\mathbf{P}$ \\
\hline
\end{tabular}

${ }^{\mathrm{z}} \mathrm{P}$, presence of PCR band. Strongly amplified bands were indicated by bold letters, while weakly amplified bands with reproducibility indicated by normal letters. 
Table 3. DNA polymorphisms among 48 accessions of radish (Raphanus sativus L.) revealed by 40 RAPD primers.

\begin{tabular}{|c|c|c|c|}
\hline \multirow{2}{*}{$\begin{array}{l}\text { Primer } \\
\text { ID }\end{array}$} & \multicolumn{2}{|c|}{ No. of bands } & \multirow{2}{*}{$\frac{\text { Polymorphism }}{\text { rate }}$} \\
\hline & Total bands & Polymorphic bands & \\
\hline A01 & 9 & 5 & 0.6 \\
\hline A03 & 9 & 4 & 0.4 \\
\hline A04 & 11 & 8 & 0.7 \\
\hline A05 & 10 & 3 & 0.3 \\
\hline A08 & 8 & 6 & 0.8 \\
\hline A09 & 10 & 3 & 0.3 \\
\hline A10 & 7 & 5 & 0.7 \\
\hline A11 & 6 & 4 & 0.7 \\
\hline A13 & 10 & 4 & 0.4 \\
\hline A15 & 5 & 3 & 0.6 \\
\hline A16 & 8 & 5 & 0.6 \\
\hline A17 & 6 & 4 & 0.7 \\
\hline A18 & 8 & 6 & 0.8 \\
\hline A19 & 10 & 9 & 0.9 \\
\hline A20 & 6 & 1 & 0.2 \\
\hline B01 & 7 & 3 & 0.4 \\
\hline B03 & 5 & 4 & 0.8 \\
\hline B04 & 4 & 1 & 0.3 \\
\hline B07 & 10 & 6 & 0.6 \\
\hline B08 & 10 & 3 & 0.3 \\
\hline B10 & 6 & 3 & 0.5 \\
\hline B11 & 10 & 4 & 0.4 \\
\hline B12 & 8 & 5 & 0.6 \\
\hline B15 & 8 & 5 & 0.6 \\
\hline B17 & 12 & 6 & 0.5 \\
\hline B18 & 11 & 9 & 0.8 \\
\hline C01 & 7 & 3 & 0.4 \\
\hline $\mathrm{C} 02$ & 8 & 6 & 0.8 \\
\hline $\mathrm{C} 04$ & 7 & 5 & 0.7 \\
\hline C05 & 8 & 7 & 0.9 \\
\hline C06 & 7 & 7 & 1.0 \\
\hline C07 & 10 & 5 & 0.5 \\
\hline C08 & 6 & 3 & 0.5 \\
\hline C09 & 10 & 5 & 0.5 \\
\hline C11 & 13 & 3 & 0.2 \\
\hline C13 & 9 & 4 & 0.4 \\
\hline C16 & 8 & 5 & 0.6 \\
\hline C18 & 5 & 2 & 0.4 \\
\hline
\end{tabular}

Differences among the accessions at the DNA level were determined by comparing the genetic similarity coefficients from the pair-wise comparisons. The genetic similarity coefficients among all pairs of 48accessions varied from 0.62 to 0.93 , and $42 \%$ of the comparisons exhibited values higher than 0.85 . All cultivars could be distinguished based on the DNA fingerprints revealed by RAPD, indicating that RAPD profiles revealed in this study can be useful for cultivar identification.

In the study of three radish varieties ( $R$ sativus var. sativus, var. hortenisis Becker, var. niger Kerner) in China using the amplified fragment length polymorphisms (AFLPs) and RAPDs, the most abundant genetic diversity was revealed among var. hortenisis Becker (Kong et al., 2011). Substantial levels of genetic variability were also detected in the germplasm of cultivated radish by analyzing AFLPs and inter-simple sequence repeats (ISSRs) (Muminovic et al., 2005). The wide genetic background harbored in 'Danji' radish can be exploited for genetic improvements of the radish germplasm. In addition, the data for S-haplotypes and genetic relationships assessed in this study will be greatly useful for deciding cross combinations to recover the unique traits of 'Danji' radish and extend its genetic diversity.

To evaluate how DNA variations at the RAPD level exist within the accessions carrying the same S-haplotype, dendrograms constructed based on RAPD and S-haplotype primers were compared (Fig. 3). When the accessions carrying S5 and S21 (Group A-1) were considered, these accessions tended to separate into two major groups (Group B-1and Group B-3). A majority of accessions harboring S2 and S5 (Group B- 2), tended to be closely related and located in GroupB-2. Four out of seven accessions harboring S23 of the SRK gene belonged to Group B-1. Accessions harboring S-haplotype with a low frequency $(47,48$, and 50 ) were distantly related with other accessions as well in the RAPD dendrogram. In general, the comparison between the two dendrograms indicates that despite the detection of unrelated and sporadic distribution for some accessions, there was a tendency for the accessions carrying the same S-allelic composition to group into the same cluster. This suggests that the accessions of the same S-haplotype may share a similar genetic background and a common parentage.

\section{Literature Cited}

Batemen, A.J. 1955. Self-incompatibility systems in angiosperms. III. Crucifierae. Heredity 9:52-68.

Kong, Q., X. Li, C. Xiang, H. Wang, J. Song, and H. Zhi. 2011. 


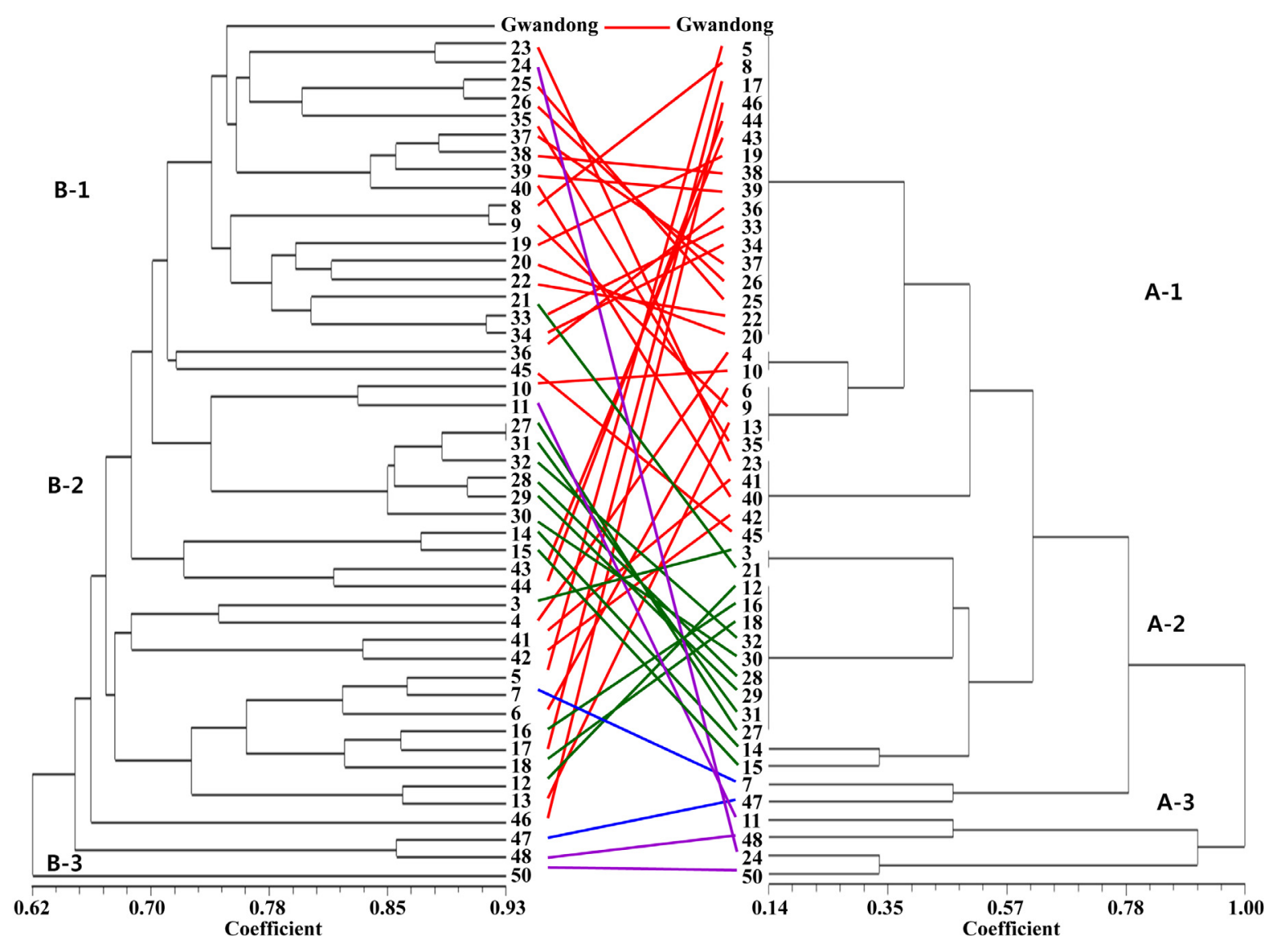

Fig. 3. Comparison of dendrograms showing genetic relationships among 47 accessions of 'Danji' radish (Raphanus sativus $\mathrm{L}$. var. hortensis) based on RAPDs (left) and S haplotype-specific primers (right). Different colors indicate accessions classified as different groups based onS haplotype.

Genetic diversity of radish (Raphanus sativus L.) germplasm resources revealed by AFLP and RAPD markers. Plant Mol. Biol. Rep. 29:217-223.

Lim, S.H., H.J. Cho, S.J. Lee, Y.H. Cho, and B.D. Kim. 2002. Identification and classification of S haplotypes in Raphanus sativus by PCR-RFLP of the S locus glycoprotein (SLG) gene and the S locus receptor kinase (SRK) gene. Theor. Appl. Genet. 104:1253-1262.

Lim, S.H., K.T. Kim, S.H. Park, H.J. Cho, H.Y. Park, S.Y. Hwang, M.K. Yoon, I.G. Mok, J.G. Woo, and D.G. Oh. 2006. Identification of S haplotypes in commercial F1 hybrid cultivars of radish by PCR-RFLP analysis. Korean J. Breed. 38:167-172.

Muminovic, J., A. Merz, and A.E. Melchinger. 2005. Genetic structure and diversity among radish varieties as inferred from AFLP and ISSR analysis. J. Amer. Soc. Hort. Sci. 130:79-87.

Nasrallah, M.E., J.T. Barber, and D.H. Wallace. 1970. Selfincompatibility proteins in plants: detection. Genetics and possible mode of action. Heredity 25:23-27.

Nasrallah, J.B., T.H. Kao, M.L. Goldberg, and M.E. Nasrallah. 1985. A cDNA cloning encoding an S locus specific glycoprotein from Brassica oleracea. Nature 318:263-267.
Nasrallah, J.B., T. Nishio, and M.E. Nasrallah. 1991. The selfincompatibility genes of Brassica: expression and the use in genetic ablation of floral tissues. Annu. Rev. Plant Physiol. 42:392-422.

Rudloff, E. 1991. Results and problems in building up Selfincompatable lines and their use in hybrid seed production of winter rape (Brassica napus L.). Proc. 8th Int. Rapeseed Cong., Saskatoon p. 107-112.

Takayama, S., H. Shimosato, H. Shiba, M. Funato, F.S. Che, M. Watanabe, M. Iwano, and A. Isogai. 2001. Direct ligand-receptor complex interaction controls Brasscia self-incompatibility. Nature 413:534-538.

Nasrallah, J.B. and M.E. Nasrallah. 1993. Pollen-stigma interaction in the sporophytic self-incompatibility response. Plant Cell 5:1325-1335.

Watanabe, M., A. Ito, Y. Takada, C. Ninomiya, T. Kakizaki, Y. Takahata, K. Hatakeyama, K. Hinata, G. Suzuki, T. Takasaki, Y. Satta, H. Shiba, S.Takayama, and A. Isogai. 2000. Highly divergent sequences of the pollen self-incompatibility (S) gene in class-1 S haplotypes of Brassica campestris (syn. Rapa) L. FEBS Lett. 473:139-144. 